Nachdruck verboten.

Übersetzungsrecht vorbehalten.

\title{
Further notes on the genus Microcotyle.
}

By

G. A. MacCallum, M. D., New York.

With 4 figures in the text.

As stated in a previous paper in this journal (Vol. 34, 1913, Syst., p. 223), one is impressed in studying the Microcotylidae with the lack of variety in the arrangement and form of the internal organs so that the differentiation of species is dependent largely upon outward differences. Of these the number, form and structure of the caudal suckers and the peculiar armature of spines which often occurs about the genital opening are perhaps the most constant and characteristic features, although of course there are many other things which must be taken into consideration in deciding this point. In the table which follows and which is a continuation of that given in the previous paper, it is attempted to give these data as accurately as possible, and it is hoped that this basis for classification will be adopted by helminthologists in the case of this genus to avoid confusion.

4 new species are added to the genus as the result of the study of the parasites of the gills of marine fishes obtained partly from the New York Aquarium, partly in the laboratory of the U. S. Fish Commission at Woods Hole and partly in the fish markets of New 
York. In the course of these studies it has seemed pretty well arranged by Nature that the parasites of the gills of fish are placed there according to families - for instance the Microcotylidae are seldom or never found on the same fish as the Octocotylidae or Acanthocotylidae. At least it is my experience that in such a family of fish as the Salmonidae the parasites on the gills will almost invariably be found to be Octocotylidae and so on.

\section{Microcotyle macroura.}

In the previous paper mentioned, a description of this form was given which, owing to insufficient material, was uncertain or incomplete in places. Since that time study of new material has made it possible to confirm or complete some of these observations. The description of the mouth, its suckers, and of the peculiar position of the small pharynx-like structure on the dorsal surface of the digestive canal is all correct. There is a rather twisted or tortuous canal penetrating the pharynx but it seems that there is also a freer and unguarded opening from the mouth directly into the digestive tract.

The intestinal coeca are extraordinarily widely ramified through the body, their diverticula opening on both sides of the main line of the channel and extending outwardly quite to the skin. Among these diverticula and in very close contact with them lie the other organs. There is hardly any lining to be made out even with high powers. The epithelial cells must be extremely thin and flat for they can nowhere be clearly discerned.

The parenchyma throughout except in the ventral part of the caudal disc is composed of large polygonal cells with relatively minute nuclei. In the caudal disc the parenchyma is largely replaced by muscle and what cells are present fill elongated spaces among these fibres.

The genitalia are precisely as described before but with the new material it was possible to trace in serial sections the continuity of the vitelline ducts with the two vaginal tubes which join as they approach the vaginal orifice and pass through a thick muscular mass to open on the dorsal surface.

In two reconstructions of the genitalia from these new serial sections the duct figured at $K$ in fig. $\mathrm{D}$ and designated as possibly the Canalis genito-intestinalis could be traced out precisely as 
it is shown there and could be shown to end blindly in the parenchyma and not in the intestine. It seems to contain spermatozoa and must therefore be put down definitely at the Receptaculum seminis. Otherwise the female genitalia proved to have been correctly described and sketched in that paper.

The only other point of interest is that the $\mathrm{W}$-shaped arrangement of chitionus rods about the cirrus opening is found to be a kind of chitinous skeleton for the muscular cirrus itself. The stouter anterior parts of these rods pierce the muscular sac obliquely and come into immediate connection with the inner protrusible tube. Outside they run quite far back and disappear near the Vas deferens. They are not so clearly outlined as it seemed from the previous material but give off twigs and branches as various places.

\section{Microcotyle pogoniae n. sp.}

The worm occurs on the gills of the common sea drum, Pogonias cromis, sometimes in such great numbers as to menace the life of the host.

The body is elongated with a large sucker disc which constitutes about one-third of the total length and which at its upper end is sharply marked off by indentations which give it almost the form of an arrow head. There are about one hundred and eight suckers which reach their greatest size at about the middle of the disc starting above with two small ones and again decreasing in size toward the caudal termination (Fig. A a). ${ }^{1}$ )

The chitinous skeleton is quite delicate and has the arrangement shown in Fig. A e. The suckers at the mouth are large and armed at their margins by a row of minute spicules. Their cavity is crossed by a partition separating it into two loculi the inner and larger of which is deeply indented at its median border (Fig. A c). Immediately posterior to these in the mid line is the peculiarly shaped pharynx which has a narrow anterior part and a more bulbous portion (Fig. Ad). A short way behind this the esophagus divides into the two lateral coeca which run far back into the caudal disc.

Directly behind the bifurcation of the intestine lies the genital pore which is unarmed and small in proportion to the size of the

1) Explanation of Abbreviations see pag. 402. 

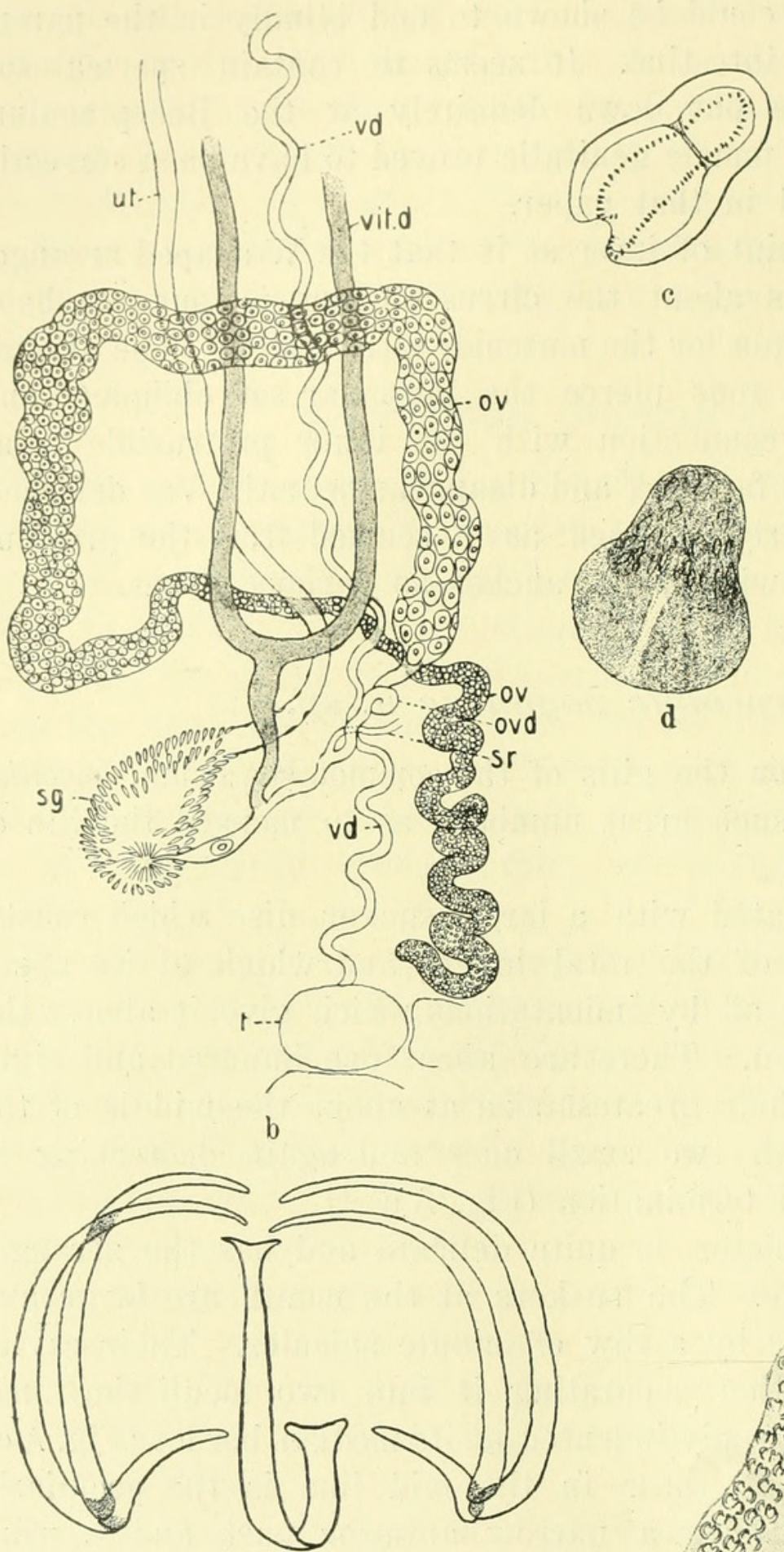

e

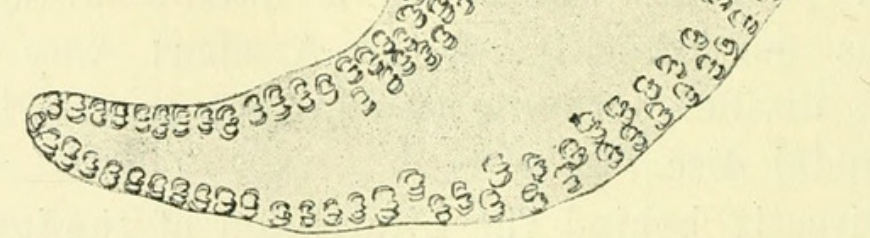

a

Fig. A. a Microcotyle pogoniae n. sp. b Detail of genital organs. c Mouth sucker. d Pharynx. e Chitinous skeleton of a caudal sucker. 
worm. It lies about $0,4 \mathrm{~mm}$ behind the oral suckers. Behind it at a distance of about $0,65 \mathrm{~mm}$ on the dorsal surface is the sac-like orifice of the vagina which is also unarmed. From this there runs backward a tortuous tube which after forming an enlargement opens into two lateral vaginal canals which eventually become the lateral vitelline ducts. Posteriorly these begin to be filled with yolk material and enlarge until they reach the point at which they unite.

The ovary (Figs A a and b) is much longer and narrower and more convoluted than in most of the other species studied. It form first an irregular square across the middle of the worm and crossing to the left side coils irregularly backward toward the left where the eggs are most fully developed and the oviduct takes its origin. This duct proceeds backward to receive the common vitelline duct but gives off on the way a canal which runs to the left. The termination of this canal could not be made out and it is not shown in the drawing but it doubtless represents the seminal reservoir. Having received the vitelline duct the oviduct passes through the radiate shell gland into the bulbous uterus which then runs straight forward to the genital opening. The vitellaria are voluminous and extend from opposite the vaginal opening to the sucker disc, occupying both sides of the body. The testes, about 75 in number, extend nearly to the sucker disc, occupying the whole of the middle of the body from the termination of the uterus backward. The Vas deferens is large and tortuous and is usually filled with spermatozoa. It passes forward to open at the genital pore without the formation of any definite cirrus.

The eggs are yellow and fusiform with one rather rounded end. This is the posterior end and is not provided with a chitinous filament while the anterior end is pointed and extended into a very long tangled filament.

Measurements are as follows:

Length of worm: 12 to $13 \mathrm{~mm}$.

Width: $1,25 \mathrm{~mm}$.

Length and form of caudal disc: $4,5 \mathrm{~mm}$ triangular.

A verage: 108 suckers.

Diam. of suckers: $0,2 \times 0,15$.

Testes: 75 in number.

Size: 0,10 to 0,15 . 
(Measurements continued)

Ova: $0,12 \times 0,5$ to $0,15 \times 0,06$.

Diam. across head: 0,45 .

Cloacal aperture: $0,04 \times 0,10$.

Diam. of vaginal opening: $0,04 \times 0,01$.

\section{Microcotyle carangis $n$. sp.}

There were found on the gills of a yellow crevalle, Caranx crysos (Mitchili), 5 examples of a Microcotyle which differs very markedly from other species.

The worm is small, measuring only $4,4 \mathrm{~mm}$ by 0,8 . The anterior end is expanded laterally and provided with a sucker at each angle of this expansion. The mouth opens directly into the comparatively small pharynx from which the short esophagus runs backward to divide into the lateral intestinal coeca which run dorsally toward the posterior extremity. A short distance behind the bifurcation is the cirrus sac which is pear shaped with a curious arrangement of spicules as shown in Fig. Ba and Fig. B f. Two small clumps of hooklets are separate from the main group which lie in front of the muscular bulb of the cirrus. The Vas deferens can be plainly seen entering the posterior end of this bulb.

Behind this lies the female genital orifice which is also armed with spicules. The posterior end of the body forms the sucker disc which is hastate in form, one side being continued forward so as to make it asymmetrical. At the point there are on each side eleven small suckers with a chitinous skleleton formed as show in Fig. Bd. At the extreme tip there are two strong hooks and between them, apparently to stiffen them, are two straight spines which extend almost as far posteriorly as the hooks, the whole being enclosed in a membrane (Fig. Be). On the right side of the body occupying the asymmetrical forward extension of the caudal disc there is a row of twenty-six much larger suckers which diminish in size as they near the body. These are of a quite different structure from any observed in other forms of Microcotyle as shown in Fig. Bc. The chitinous skeleton is so asymmetrical in form as to give the sucker almost the appearance of some gamopetalous flower.

The ovary lies across the middle of the body as an irregular U-shaped structure placed with the convex side toward the head 
(Fig. Bb). The oviduct arises at its left end and passes backward toward the extremity of the uterus. On its way it is first joined

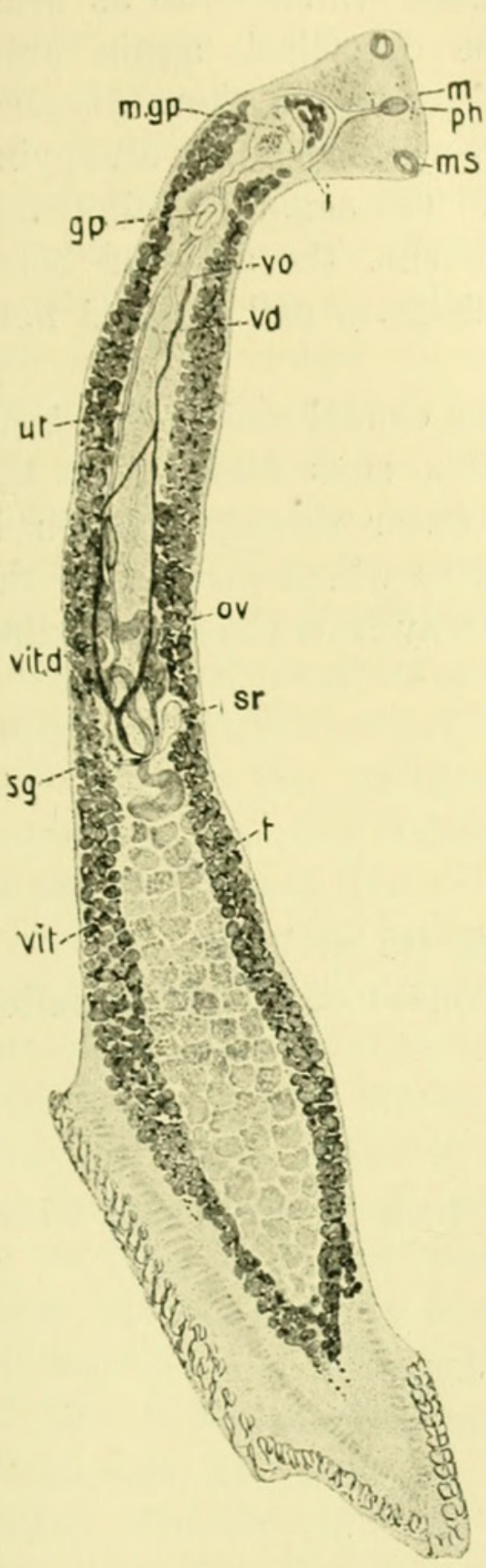

a

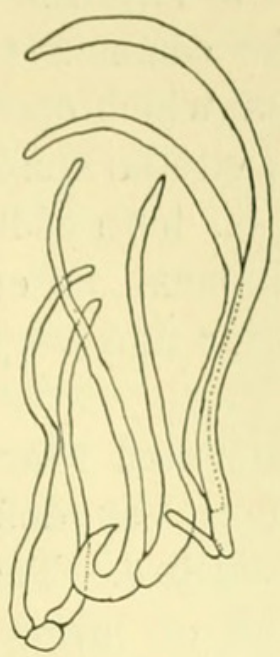

c

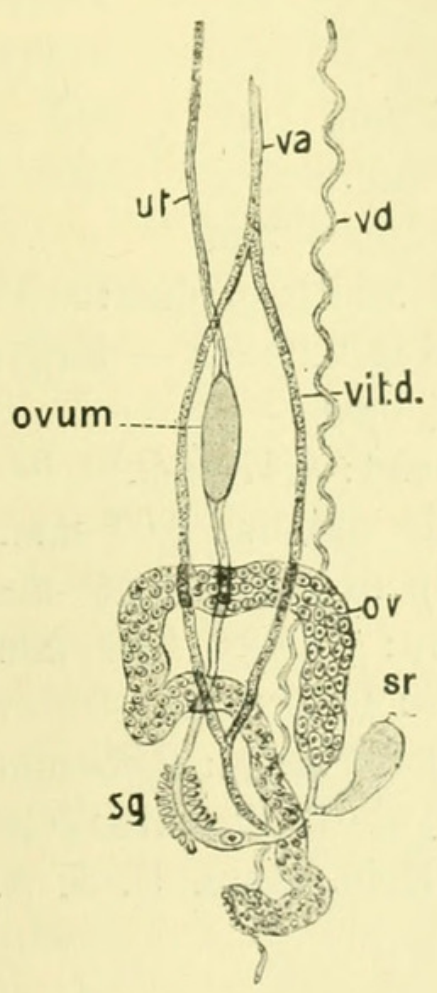

b

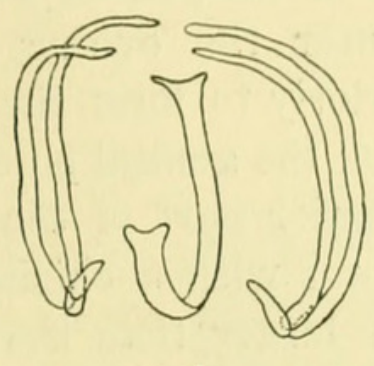

d

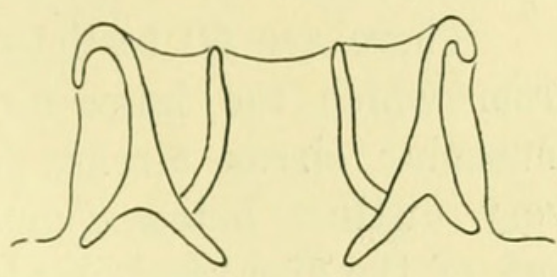

e

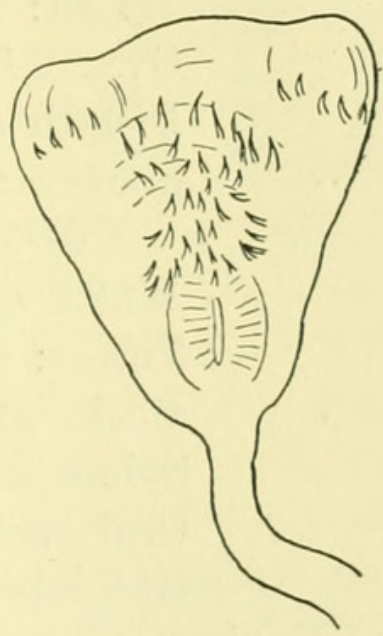

f

Fig. B. a Microcotyle carangis $n$. $s p$. b Detail of internal genital organs. $c$ and $d$ Chitinous skeleton of a caudal sucker. e Caudal spines. f Cirrus sac.

by the canal from a seminal reservoir which lies close to the end of the ovary and between it and the first row of testes. It next received the duct from the vitelline glands and then passes into 
the ootyp which is surrounded by the shell gland. From this point the tube passes forward along the right inner margin of the vitellaria to the genital pore. The vitelline ducts, which unite as usual to enter the oviduct by the common tube described, again unite anteriorly to form the vagina which opens dorsally a short distance behind the genital pore. The vitellarium is very voluminous occupying the major part of the body on both sides. The eggs are yellow and fusiform with a chitinous filament at each end, the anterior being much larger than the posterior and very delicate and tangled near its end.

There are 60 testicles situated near the caudal end of the body from which the large tortuous Vas deferens runs forward to the muscular cirrus already described. The water vascular system is very distinct being composed of large ducts which proceed to the end of the disc receiving branches on their way from the surrounding tissues.

Measurements :

Length: $4,4 \mathrm{~mm}$.

Width: $0,8 \mathrm{~mm}$.

Ova: $0,11 \times 0,03 \mathrm{~mm}$.

Length and width of disc: $0,9 \times 0,5$ at base.

Suckers : 48 in number - larger ones $0,05 \times 0,07$; smaller $0,04 \times 0,03$.

Width of head: $0,47 \mathrm{~mm}$.

Testes: 60 in number $0,07 \mathrm{~mm}$.

Hooks at tip of disc: $0,029 \mathrm{~mm}$ long $\times 0,002 \mathrm{~mm}$ wide. Spines at tip: $0,15 \times 0,01 \mathrm{~mm}$.

Oral suckers: $0,04 \mathrm{~mm}$.

Hooklets around g. p.: $0,05 \mathrm{~mm}$ long.

Habitat: Gills of yellow Crevalle (Caranx crysos).

Location: Woods Hole, Mass. U. S. A.

\section{Microcotyle angelichthys n. sp.}

A worm closely related to others to be described but differing in one or two important particulars is found on the gills of the Angel fish, Holacanthus ciliaris, in numbers varying from a few to many thousands or enough to cause the death of its host.

It is small measuring $4,3 \times 0,3 \mathrm{~mm}$ with a caudal sucker disc about $1 \mathrm{~mm}$ long armed with forty to sixty suckers (Fig. Ca). The 
terminal mouth is flanked by suckers which have a central partition. The pharynx is large but rather delicate in structure opening into a short esophagus which divides in front of the genital pore. The genital pore itself is situated very near the anterior end of the body. It opens into a rounded sac thickly armed with spicules especially closely set round the aperture. There are two smaller groups of spicules placed laterally behind and the sac is surrounded by radiating muscle fibers (Fig. Cb). The uterus and Vas deferens open into this sac, the latter through a delicate bulbous structure which appears to extend forward beyond the end of the uterus. The vaginal orifice lies behind and in the mid-dorsal line.

One important respect in which this worm differs from the other Microcotylidae, is the fact that while in almost all of the others the ovary is placed across the middle of the body in the form of a long convoluted tube, in this case it is a more or less globular mass like that of the distomes placed on the right side just anterior to the testes. On the right side above this may be plainly seen the seminal reservoir and also its duct joining the oviduct. The shell gland is in the usual position behind or beside the tail

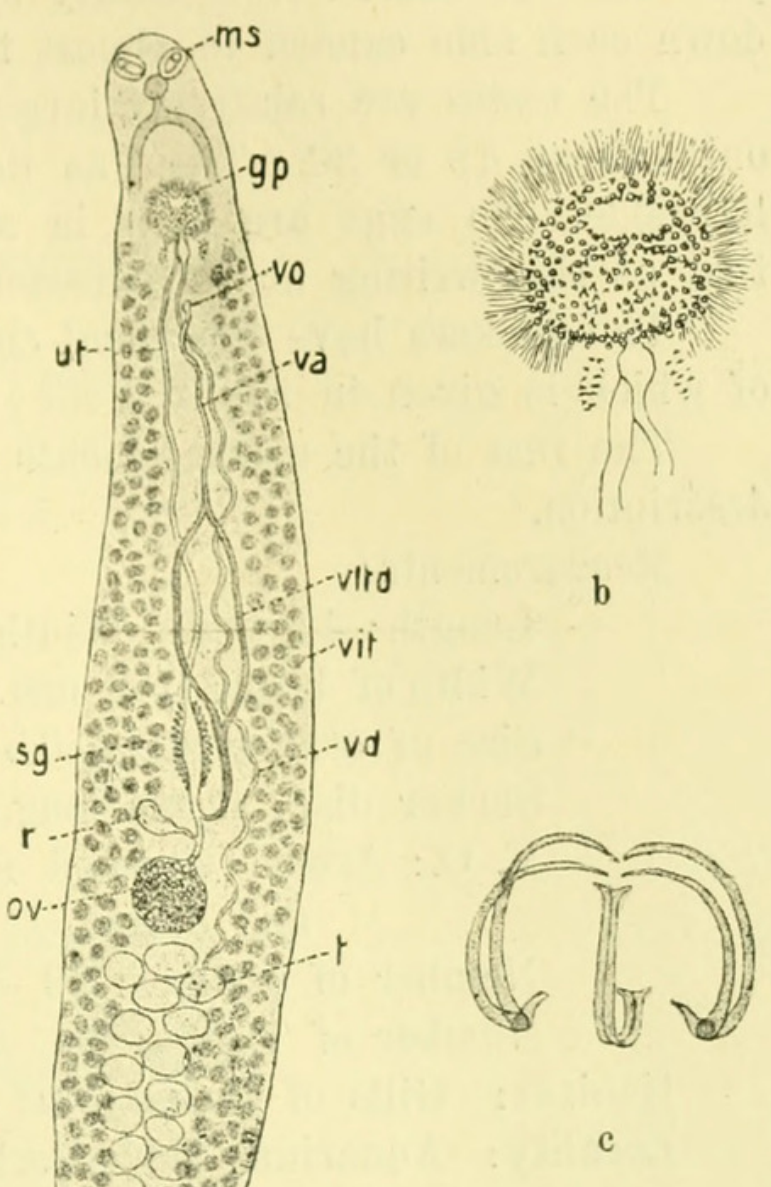
of the Y-shaped vitelline reservoir. The oviduct is apparently given off the ovary toward the middle of the worm and receives the duct from the spermatheca and vitelline reservoir before entering the 
beginning of the uterus. The uterus, surrounded here by a mantle of shell gland cells, makes its way upward toward the genital pore along the inside of the right vitellarium. The vitellaria are very plentiful and extend from nearly opposite the orifice of the vagina down each side caudad to almost the sucker disc.

The testes are relatively large but few in number, there being only about 18 or 20 . The Vas deferens passes anteriorly on the left side. No eggs are seen in any of the specimens mounted so that at this writing no measurements of them can be given.

The suckers have the usual chitinous reinforcement, a drawing of which is given in Fig. C c.

The rest of the measurements etc. are given at the end of this description.

Measurements :

Length: $4,4 \mathrm{~mm}$. Width: $0,3 \mathrm{~mm}$.

Width of head: $0,12 \mathrm{~mm}$.

Size of oral suckers: $0, \check{\mathrm{mm}}$.

Sucker disc: $1 \mathrm{~mm}$ long, $0,4 \mathrm{~mm}$ wide.

V. O.: Armed situated short distance posterior to g. p. and dorsal.

Number of suckers: $59-0,03 \times 0,02$.

Number of Testes: $20-0,06$.

Habitat: Gills of Holacanthus angelichthys.

Locality: Aquarium, New York.

\section{Microcotyle archosargi $n$. sp.}

This form is to be found on the gills of the marine Sheep's head, Archosargus probatocephalus, and is so delicate as to be almost invisible when alive and in situ. It measures 8 by $0,8 \mathrm{~mm}$ and is much elongated, becoming very slender just in front of the asymmetrical spreading caudal disc (Fig. Da).

The mouth is terminal and supplied with the usual lateral suckers which are provided with a marginal membrane and subdivided by a distinct partition. The delicate pharynx passes into a short esophagus which gives rise as usual to two intestinal rami.

The common genital pore is surrounded by spicules which are arranged as shown in the figure (Fig. Dc). Almost immediately behind this on the dorsal surface lies the opening of the vagina, also surrounded by an armature of spicules. 
Further notes on the genus Microcotyle.

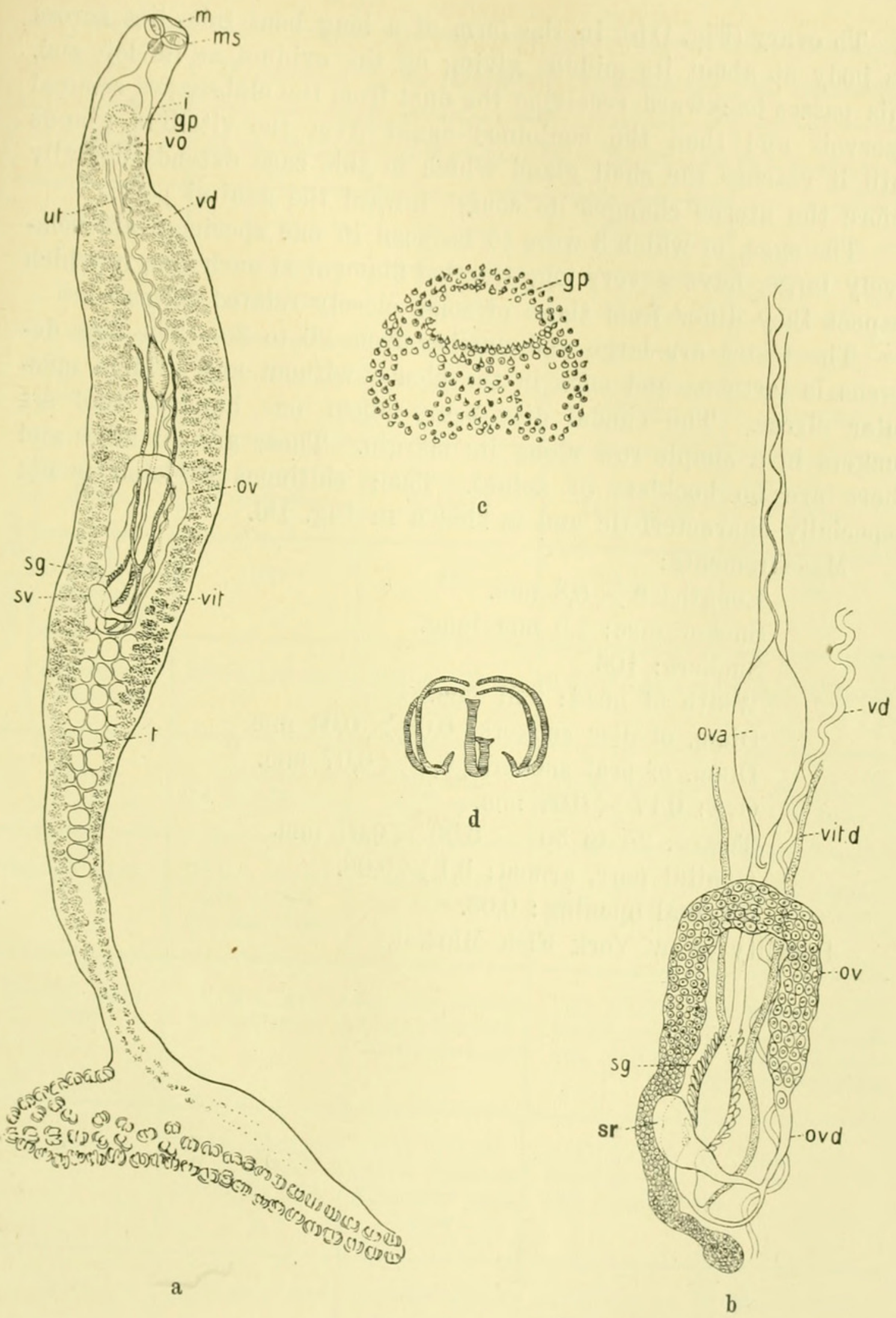

Fig. D.

a Microcotyle archosargi $n . s p$. b Detail of internal genital organs.

c Armature of genital pore. d Chitinous skeleton of a caudal sucker. Zool. Jahrb. XXXV. Abt. f. Syst. 
Th ovary (Fig. D b), in the form of a long bent tube lies across the body at about its middle, giving off the oviduct at its left end. This passes backward receiving the duct from the clubshaped seminal reservoir and then the conjoined canal from the vitelline glands until it reaches the shell gland which in this case extends dorsally before the uterus changes its course toward the genital pore.

The eggs, of which 3 were to be seen in one specimen are relatively large, have a very long tangled filament at each end, in which respect they differ from those of some closely related forms.

The testes are large and number from 20 to 35 . The Vas deferens is tortuous and ends in the cloaca without any evident muscular cirrus. The caudal disc bears about one hundred and six suckers in a simple row along its margin. These are all alike and there are no hooklets or spines. Their chitinous skeleton is not especially characteristic and is shown in Fig. Dd.

Measurements :

Length: $8 \times 0,8 \mathrm{~mm}$.

Sucker disc: 1,5 mm lang.

Suckers: 106.

Width of head: $0,21 \mathrm{~mm}$.

Diam. of disc suckers: $0,08 \times 0,04 \mathrm{~mm}$.

Diam. of oral suckers: $0,1 \times 0,07 \mathrm{~mm}$.

Ova: $0,17 \times 0,07 \mathrm{~mm}$.

Testes: 25 to $35-0,09 \times 0,07 \mathrm{~mm}$.

Genital pore, armed: $0,1 \times 0,08$.

Vaginal opening: 0,03 .

Locality: New York Fish Market. 
Further notes on the genus Mircocotyle.

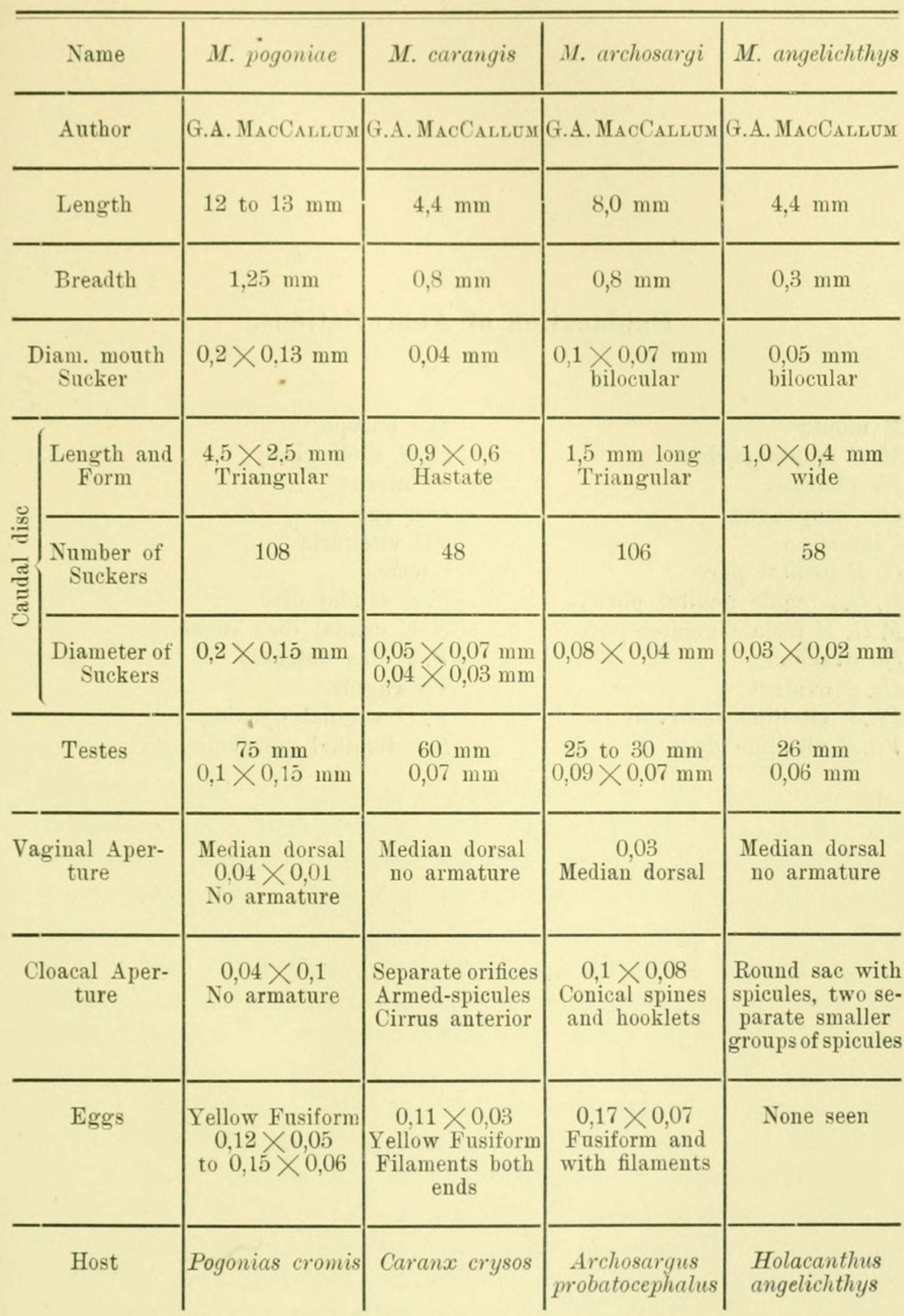




\section{Explanation of Abbreviations.}

$M$ mouth

$M$. $S$ mouth sucker

$P h$ pharynx

Oes esophagus

$i$ intestine

G. $P$ genital pore

M. G. $P$ male genital pore

F. $G$. $P$ female genital pore

$O v$ ovarium

Ov. $d$ oviduct

Vit. $r$ vitelline reservoir

Vit. $\dot{d}$ vitelline duct
Oot ootype

$S . G$ shell gland

$U t$ uterus

Ova egg

Vit vitellaria

$t$ testes

C. $d$ caudal disc

S. $C$ caudal disc sucker

V.d Vas deferens

$\mathrm{Va}$ vagina

$V$. $O$ vaginal opening

$S . r$ seminal reservoir 


\section{$2 \mathrm{BHL}$ Biodiversity Heritage Library}

MacCallum, George Alexander. 1913. "Further notes on the genus

Microcotyle." Zoologische Jahrbücher 35, 389-402.

https://doi.org/10.5962/bhl.part.16720.

View This Item Online: https://www.biodiversitylibrary.org/item/37611

DOI: https://doi.org/10.5962/bhl.part.16720

Permalink: https://www.biodiversitylibrary.org/partpdf/16720

\section{Holding Institution}

MBLWHOI Library

Sponsored by

MBLWHOI Library

\section{Copyright \& Reuse}

Copyright Status: NOT_IN_COPYRIGHT

This document was created from content at the Biodiversity Heritage Library, the world's largest open access digital library for biodiversity literature and archives. Visit BHL at https://www.biodiversitylibrary.org. 